\title{
Remote Telephone Interpretation in Medical Consultations with Refugees: Meta-communications about Care, Survival and Selfhood
}

\author{
CHRISTINE PHILLIPS \\ Social Foundations of Medicine, ANU Medical School, Australian National \\ University; Companion House Medical Service, Cook, Australian Capital \\ Territory \\ Christine.phillips@anu.edu.au
}

MS received May 2012; revised MS received January 2013

\begin{abstract}
In Australia, interpreted consultations with refugees are frequently conducted using remote telephone interpretation (RTI). This article explores the metacommunication, or communication about communication (Bateson 1951), which occurs in these consultations. Consultations using RTI are framed by two types of meta-communication: one between patient and doctor about the state's responsiveness to the refugee, and a second communication between refugee and interpreter about survival of the self through resettlement. The latter is established through the introductory chat of the interpreter, the everyday soundscapes of the interpreters' lives heard in the background, and the more assertive speaking style used by remote interpreters. Together, they produce a meta-communication about the safe negotiation of identity through resettlement. A range of technological alternatives to RTI exist or are in development. We should be wary that newer technologies which make human-tohuman interpreting redundant do not result in a more restricted communication environment for refugees.
\end{abstract}

Keywords: translating, refugees, human migration, remote consultation

\section{Introduction}

Health care is a core component of successful integration programmes for resettled refugees (Ager and Strang 2008), but ensuring equitable access to health care services remains challenging. In Canada (McKeary and Newbold 2010), the UK (Aldous et al. 1999) and Australia (Correa-Velez et al. 2007), refugees have been shown to under-use services in comparison with the rest of the population. National tracking data in Canada showed that in the first six months of resettlement, one-fifth of refugees reported difficulties in 
accessing health care, with language being one of the major barriers to access (McKeary and Newbold 2010).

Research to improve health care access for refugees routinely calls for enhanced and wider use of interpreters. In a survey of 495 primary care physicians working in an area of linguistic diversity in southern California, professional (telephone or on-site) interpreters were reported to be used for only 6 per cent of non-English-speaking patients (Hornberger et al. 1997). The cost of hiring interpreters was cited as one reason for low use in this study, but in other settings where cost barriers have been removed, interpreters are still under-used. In Australia, for example, which has a national free telephone interpreter service for doctors in private practice, the service is estimated to be used in only one in every 100 private practice consultations for persons with limited English proficiency (Phillips and Travaglia 2011). In two studies conducted in hospitals with 24 hour access to on-site interpreters in the USA, physicians frequently did not use interpreters, preferring to use their own language skills or those of other health workers (Burbano O'Leary et al. 2003; Yawman et al. 2006).

The medical consultation is already a site in which power differentials exist between patient and doctor. For survivors of war and conflict the consultation may reproduce past experiences of maltreatment or neglect by persons in authority, including health workers. The use of competent and effective interpreters is one way in which health services may be able to build trust. In the past decade there has been an emerging research endeavour exploring the communicative function of the on-site interpreter (Greenhalgh et al. 2006; Leanza et al. 2010), and the role of the hospital interpreter as a gatekeeper to services (Davidson 2000, 2001), though this research has not focused on refugees. There has been little analysis of the communicative function and roles of the remote interpreter (Ko 2006).

This represents a significant gap in the literature. Health systems have little capacity to provide on-site interpreters for patients with poor proficiency in English outside urban settings or hospitals; and even in these settings they cannot cover all the languages of migrant patients. Remote telephone interpreting offers a technological solution for countries with dispersed, multilingual populations, typical of many refugee resettlement countries. There is now a global industry push to develop infrastructure and staffing for RTI services. In 2012, the market for outsourced language services was estimated to be worth around US\$33.25 billion, with telephone interpreting services accounting for an increasing proportion of the total language services market (Kelly et al. 2012).

Remote telephone interpreting is likely to have particular utility for newlyresettled refugees, who often speak languages which are not spoken by available on-site interpreters. In the USA, Language Line Services reported one-year increases in some cities of between 855 and 1000 per cent in the use of interpreters speaking Nepali, Kirundi and Hmong, reflecting local resettlement of refugees speaking these languages (Language Line 2010). Similarly, 
the Australian Translating and Interpreting Service reported that in 2009-2010, seven of the top ten languages sought through the Doctors Priority Line were those of newly arrived refugee communities (Translating and Interpreting Service 2010).

This article examines readily-accessible remote telephone interpreting in the resettlement experience of refugees. It focuses on the use of this technology in medical consultations, drawing on over a decade of experience using telephone interpreters in a refugee health service, and an audit of 265 consecutive interpreted calls. The article begins with a description of Australia's Translating and Interpreting Service and the technologies and techniques of remote interpreting. I then outline Bateson's notion of meta-communication, or communication about communication, and apply it to RTI-mediated medical consultations with newly arrived refugees. I conclude with a discussion of emerging communicative technologies and their potential impact on the resettlement experience.

\section{Remote Telephone Interpreting}

\section{Technologies of RTI}

Large-scale RTI was pioneered by the Australian Department of Immigration, which established the national Translating and Interpreting Service (TIS) in 1973. The technologies underpinning remote interpreting developed rapidly through the 1990s, as the cost per service became cheaper (Andres and Falk 2009). RTI can be conducted using simultaneous interpretation (the interpreter interprets the speech of both patient and doctor at the time they are spoken), or consecutive interpretation (the interpreter interprets after the patient or doctor has spoken). Medical consultations tend to use consecutive interpretation.

Whether simultaneous or consecutive, interpreters can work in three-way mode (all parties are connected by telephone and are physically remote from one another) or two-way mode (the interpreter is remote, but the other two parties to the communication are in the same room), either through speakerphone or a dual handset phone, or 'telephone passing' (the two parties pass the telephone back and forth between them). Interpreters report that of these three communication modes, 'telephone passing' is the most complex and least satisfying as the interpreter is obliged to act as an emissary of two parallel communications (Rosenberg 2007).

Platforms based on voice-over internet protocol (VOIP) do not provide sufficient speech quality for good RTI, particularly in three-way mode (O'Hagan and Ashworth 2002). Speakerphones can be difficult for interpreters if there is background noise (Kelly 2008), or if they do not accommodate overlapping conversation, as is often the case with speakers on mobile telephones. Consulting rooms need to be adequately soundproofed so that privacy is preserved when using a speakerphone. 


\section{Technical Aspects of RTI}

Working remotely can be exhausting for interpreters, particularly if they use conventional phones rather than headsets or speakerphones (Ko 2006). Some studies have reported the lack of visual cues to be a problem for remote interpreters, though Ko (2006) found that experienced interpreters with good equipment did not feel lack of visual cues to be a disadvantage. Telephone interpreters often have a more overt presence within the consultation, and may be more active in interrupting conversations and signalling turn-taking (Wadensjö 1999; Hsieh 2006). The interpreter's presence is further emphasized by the tendency of telephone interpreters to use third person, rather than first person, interpreting, in order to indicate which speakers are being interpreted (Hsieh 2006).

Telephone interpreters are often regarded by doctors as the 'stop-gap' solution, with on-site interpreters being the mark of good quality practice (Kuo and Fagan 1999; Locartis et al. 2010). Hsieh and Hong (2010) found that health professionals expect interpreters to provide emotional support for patients, an expectation that can only be fulfilled if the interpreter is able to establish and build upon personal rapport with the patient. Since telephone interpreters do not have a physical presence in the consultation, they may be viewed by some health professionals as of less value. For some interpreters, however, the lack of personal contact in an RTI-mediated consultation may be an advantage. The clinical settings in which they interpret may be overwhelming and traumatizing, and the distance afforded by RTI may ensure their work remains sustainable (Kelly 2008: 86). Telephone interpreters may be able to work across gender lines or with people who may view their own cultural background as in conflict with that of the interpreter, in ways that an on-site interpreter could not (Kelly 2008: 85).

In the few studies examining patient satisfaction with different types of interpreter, patients were found to prefer RTI (Hornberger et al. 1996) or to be equally satisfied with RTI and on-site interpreting (Locatis et al. 2010) or RTI and language-concordant doctors (Lee et al. 2002). Remote interpreters provide more rapid access to a wide range of languages, and patients from small language communities may feel more confident about confidentiality with a remote interpreter (Jones and Gill 1998). Many newly arrived refugees speak languages for which there is little established language capability (Phillips and Travaglia 2011). They are likely to have established community relationships with onsite interpreters. Many therefore elect to use an anonymous telephone interpreter from a different city.

\section{Australian RTI Services}

The Australian Translating and Interpreting Service (TIS) has expanded to cover over 160 languages, and is available 24 hours a day. The Doctors Priority Line provides rapid-access, fee-free interpreters for services rebatable under the national health insurance system, Medicare; in other words, it is 
freely available to all doctors working in the private sector. Free interpreting services through TIS can also be accessed by non-profit NGOs, local government authorities seeking to discuss essential services, trade union officials, the federal emergency management service, and pharmacists. Hospitals and community health services in Australia are funded through the states and territories, and most contract their own language support services, which provide RTI when needed (Phillips 2010).

Australia is a geographically dispersed, highly multicultural society, at once one of the world's most multilingual and monolingual countries (Phillips 2010). Not surprisingly, remote interpreting is undergoing a boom. In the 2011/2012 financial year, TIS provided 1,111,283 RTI services, an increase of 18 per cent on the year before. This outstrips their delivery of on-site interpreter services, which experienced a modest increase from 59,000 to 65, 242 over the same period (Department of Immigration and Citizenship 2012). The private RTI industry is also growing. In 2012, the industry analyst Common Sense Advisory rated ONCALL Interpreters and Translators, the service contracted by government health services in two of Australia's largest states, as the twentieth most profitable language service provider globally (Kelly and DePalma 2012).

Most remote interpreters have had some formal training, and are accredited through the National Accreditation Authority for Translators and Interpreters. TIS contracts over 1,500 interpreters throughout the country, and can generally access an interpreter within three minutes. Interpreters usually work as casual contractors to TIS, indicating their availability for work by logging into an automated system. They frequently mix interpreting with other daily activities such as work, study or family life. The Department of Immigration and Citizenship has an ongoing programme to identify and support speakers of over 70 'newly emerging' languages - almost all of which are from refugeesource countries - to train as interpreters for TIS (National Accreditation Authority for Translators and Interpreters 2010).

TIS is a highly accessible system, and there is an increasing expectation among professional groups and medical indemnity associations that doctors have the skills and knowledge to access and use remote interpreters (Bird 2008; Invivo 2008; Medical Board of Australia 2010). The ability to access an interpreter is now tested as part of the accreditation process for general practices (RACGP 2010). Between the 2007/2008 financial year and the $2010 / 2011$ financial year the annual use of TIS remote interpreters for medical consultations increased by 45 per cent to nearly 30,000 services (Department of Immigration and Citizenship 2011).

\section{Methods}

\section{Setting}

The analysis in this article draws on 12 years of clinical experience in a refugee health service and over 4,500 RTI-mediated medical consultations. The refugee 
health service is based in a medium-sized city, and provides screening and subsequent primary health care for refugees in the first 18 months after resettlement. The source countries for the refugee populations served by this clinic over the last 12 years include Afghanistan, Bosnia, Burma, Iran, Iraq, Sierra Leone and Sudan. Most consultations use TIS remote interpreters. Consultations often occur in family groups, in which one interpreter may be interpreting for up to six people in one consulting room.

\section{Data Collection}

Data collected for this study include a consecutive audit of background sounds and other communication not related to the consultation, as related to the doctor by either the patient or the interpreter, during RTI-medicated consultations over ten months in $2011(\mathrm{n}=265)$. Interview data reported in this study were collected for a separate project aiming to develop principles and performance indicators for refugee health services, in which a purposive sample of eight refugees who had arrived in the preceding two years were interviewed about their perceptions of good health care. Interviews were conducted in English, and were recorded by a scribe. This element of the project was approved by the Board of Companion House as a quality improvement exercise. The records of conversation between interpreter and doctor were constructed as typical cases, and were checked for veracity with other clinicians experienced in working with remote interpreters.

\section{Analysis}

Audit, interview and conversation data were analysed using thematic analysis. The first stage of coding involved cross-coding the audit and interview data, developing and testing evolving themes within the meta-communication framework. The case studies of conversation were then established and tested for robustness of concept about relational and episodic meta-communication with colleagues who were experienced in refugee health and using interpreters.

\section{Meta-communication in the Medical Consultation}

Meta-communication is the 'communication about communication' that describes the framing of communicative interaction. The original concept elaborated by Bateson (1951) distinguished message and meta-message as different dimensions of communication, with the latter occurring at a higher, more encompassing level. Meta-messages are conveyed through meta-communication. Meta-communication functions as a guide to interpretation, to understanding the framing, context and shifts in linguistic and other performance modes which occur in a communication (Bauman 1975). Parties to communication establish meaning through reading and reconciling the interplay of message and meta-message. Meta-communication may be 
implicit - through gesture, expression, or the cultural framing of a communication-or explicit.

Wilmot (1980) extended Bateson's concept to argue that there were two types of meta-communication: relational and episodic. Relational meta-communications are 'those that arise from our ongoing encounters with another' (Wilmot 1980: 63). Meanings can be built implicitly through ongoing communications, with messages conveying an evolving statement about the relationship of one speaker to another. Meanings can also be built explicitly through statements about relationships. A health worker who states 'I'm the person who will help you to get well' is making a meta-communication about the assumption of a long-term therapeutic responsibility, beyond the short-term deployment of knowledge and skills. Many relational meta-communications describe dominant/subordinate relations. For example, the conversation on a ward round between a doctor and a patient lying in a hospital bed conveys a meta-communication about authority and its exercise. Wilmot points out that research has focused on meta-communications about power, while ignoring other relational meta-communications, particularly those conveying love/hate relationships. This last type of relationship is marked by a different set of emotions and social connections, to do with care and attentiveness, neglect and disdain.

Episodic meta-communication refers to the events that occur within each communication that help make sense of the communication. In contrast to relational meta-communication, episodic meta-communication does not require ongoing encounters, but instead indicates an implicit message of 'this is how I see you at this point in time for the purposes of interpreting my messages' (Wilmot 1980: 64). Process-oriented statements ('I'm only joking', 'You're interrupting me') are episodic meta-communications that convey in the first case, a wish to discount the content of a message, and in the second case, the urgency of the message, or the perceived lack of communicative space provided by the interlocutor. Episodic meta-communication can also be implicit, through gestures, or interruptions to the flow of speech.

The medical consultation is a stylized form of communication, in which the doctor and the patient negotiate a series of semantic steps to reach an agreed understanding, usually about illness and its treatment. As a cultural system, biomedicine has achieved such global dominance that the broad elements of the consultation-symptom exchange, problem formulation, diagnosis, and agreed solution (Pendleton et al. 2003) - are recognizable across cultures. The newly arrived refugee is likely to recognize the stylistic conventions of the medical consultation, even when this is not conveyed in their own language.

Meta-communication in the medical consultation, on the other hand, is influenced by the context and the social positions of the communicators. Most refugees consult a doctor early in the resettlement process, when they are likely to be wrestling with complex feelings related to resettlement, including a loss of sense of agency, grief and concern for family who have not been 


\section{Christine Phillips}

resettled, and sometimes an increase in fear and sadness. The introduction of the interpreter into the communication allows two-layered and subtle metacommunications to occur: a relational level meta-communication about care and awareness of the newly arrived person, and an episodic level meta-communication about survival and selfhood.

\section{Meta-communication about Caring}

The RTI-mediated consultation begins with the doctor or receptionist asking the patient if they would like an interpreter, or by checking that they can hear and understand the pre-booked interpreter. Either conversation communicates specific recognition of the needs of the patient.

In the following quote, an East African woman describes, in English, being 'given speech' through the arranging of a remote interpreter. The provision of an interpreter by the service is presented as analogous to the reception country itself taking on a responsibility to care.

When I came, I got to Australia, I saw it was a good country for services. When we joined the people in [health service], all the time they welcomed us. If I didn't know how to speak then they spoke by using an interpreter... They [health workers] gave advice on how to stay, and how Australia wants us to settle in. If you come and are not in good health, if somebody comes with a bad disease, they can send you somewhere. If you cannot see well, because of diet or age, they can find you an optometrist (female, from East Africa).

The remote interpreter is not individualized in this account, but instead becomes part of a larger endeavour focused on meeting settlement needs. The advice on 'how Australia wants us to settle in' refers to provisions for housing and income support. The speaker makes an immediate connection between being given attention through the means of an interpreter, and then the provision of other elements of settlement.

The meta-communication about care and attention provided by the state is thrown into relief in consultations using RTI. On-site interpreters frequently articulate their individual roles as advocacy (Hsieng 2006), as do doctors (Hsieng and Hong 2010). The meta-communication about care can sometimes be reduced to one about the individual on-site interpreter's care and attention. The opposite occurs with remote interpreters. The remote interpreter is anonymized by the institutional processes typical of RTI, where interpreters provide only their first name. Expectations of ongoing support are further undermined by the practice of not providing the full name of the patient to the interpreter. Continuity in relationships between interpreters and patients is obviated by the convention of not referring to previous consultations with the patient when the same interpreter may have been engaged. Each consultation is treated as a fresh communication between participants where the only continuity of care exists between doctor and patient. Attempts by interpreters to guess the identity of the patient are regarded by the contracting agency as 
such serious breaches of good practice that they have resulted in interpreters being fired.

Patients also participate in this conscious anonymizing of the interpreter. For many years there was only one interpreter available nationally who spoke the language of a local refugee community. This interpreter was also a wellknown leader in the local community, and he had an identifiable speech defect. He had chosen to work as a remote interpreter in order to distance himself from advocacy expectations, and to preserve the impression of confidentiality. All the refugees in the local community for whom he interpreted knew who he was, and he must have known them, but for the period of the consultation everyone participated in the fiction that this was an anonymous interpreter whose presence did not impinge on the rapport between the doctor and patient.

The 'helping identity' of the interpreter is thus suppressed in RTI. At the same time, the larger context in which help is provided by the reception country and its services is brought to the foreground. In a study exploring the settlement experiences of five refugee families in Queensland, several respondents commented on the sense of welcome provided by the service actively going out of its way to arrange interpreters:

When I saw the GP he requested an interpreter... he asked me properly and friendly and then gave me treatment. It was helpful for me (Peterson et al. 2010: 6).

The meta-communication about care and responsiveness to the individual conveyed through the use of RTI is reinforced by the growing presence of RTI in the settlement experiences of refugees. Over the last five years, there has been a near-doubling of the annual number of RTI services provided through TIS. Free RTI services were extended to private pharmacies in 2008 and, to date, a quarter of Australian pharmacies have registered for RTI services. In 2011, a pilot programme to provide telephone interpreting services to real estate agencies attending to refugees seeking private rental accommodation was judged so successful that it was expanded to regional areas (Department of Immigration and Citizenship 2012).

Although it represents a concerted and laudable effort to attend to the needs of newly arrived refugees, the expansion of RTI services may not always result in a meta-communication about support. Private and public health services frequently do not provide interpreters, even when they are requested (Phillips and Travaglia 2011; Huang and Phillips 2009). Failure to provide interpreters - particularly if a patient is aware that other services are able to organize them-conveys a meta-communication about failure to care, as in the following account where neglecting to get an interpreter presages the representation of the health system as ignoring the refugee's particular circumstances.

The first time I come to Australia, I had a backache. I went to a Chinese doctor, my uncle took me there, because I didn't know anywhere. They 


\section{Christine Phillips}

didn't get an interpreter. They charged me $\$ 45$ to see doctor and told me to get an $\mathrm{x}$-ray for $\$ 245$. I told him I only came to Australia two weeks ago, how can

I have the money? (male, from Vietnam).

The meta-communication about care can be categorized as relational, as it is established through the repeated communications of the refugee with health services. The individual identity of the interpreter is irrelevant for this metacommunication. In the next section I discuss the meta-communication that arises between the refugee and the remote interpreter, which is episodic in nature and deals with survivorship through resettlement.

\section{Meta-communication about Survivorship and the Self}

One of the challenges of resettlement for refugees is the preservation of social identity through a resettlement process that may rupture established identities such as patriarch, matriarch, provider, or elder. The medicalization of trauma may compound this process by proposing that events of the past inevitably damage the present self (Colic-Peisker and Tilbury 2003; Marlowe 2010; Fassin and Rechtman 2009). A qualitative study of Sudanese refugees noted that reliance on salient beliefs such as religion, focusing on the future, and cognitive strategies such as reframing enabled refugees to cope with difficulties through all phases of migration (Khawaja et al. 2008). Resettlement processes that reinforce the agency of refugees appear to result in less acculturation stress than those which support passive adjustment (Colic-Peisker and Tilbury 2003).

Remote interpreters for newly resettled refugees frequently share their backgrounds. Although they are anonymized through the institutional processes described in the previous section, the consultation is fretworked with coded speech and sound intrusions that instantiate survival. These metamessages are almost entirely provided firstly, through the communication style of the interpreter and secondly, through the interpreter's narrative (when presented) and the background soundscapes emerging from the interpreter's line. The first conveys a meta-communication about the spoken authority of a person from the refugee's background, while the second conveys a meta-communication through analogy about productive resettlement. Together they form a larger meta-communication about survivorship and the establishment of social identity.

Telephone interpreters, in contrast to on-site interpreters, tend to use the third person and to interrupt communication more than onsite interpreters. Telephone interpreters frequently use linguistic codes that indicate that they are about to begin or end a segment of speech. For example, a typical communication between a telephone interpreter and doctor might begin with a call-andresponse utterance with both doctor and patient, 'Hello?' or 'OK?' to indicate that they are about to begin interpreting the patient's comments into English.

Interpreter: [Communication in language with patient, then in English]. Hello? Doctor: Hello. 
Interpreter: She says that the headache is on both sides of her head and feels like throbbing.

This is a fairly passive linguistic strategy for establishing a verbal presence. Telephone interpreters may also introduce themselves into the consultation more actively at different stages of the communication by interrupting both parties to the consultation. At the beginning of the consultation, they may ask both doctor and patient to rearrange their positions so that they can hear them. The following typical exchange occurs after the doctor has turned up the volume button and moved closer to the speakerphone, and subtly introduces another authoritative presence into the consultation - signalled by the fact that it is the interpreter who does the introductory greetings to doctor and patient.

Doctor: Is this OK? Can you hear me now?

Interpreter: Yes, that's much better. Hello. [to patient] As-salaam aleikum.

At other points during the body of the consultation, the interpreter may interrupt, particularly if the communication has become lengthy, or there are elements that require clarification (instructions for taking medication, for example). While an on-site interpreter might have interrupted with a gesture, the telephone interpreter has to do this verbally, and this on occasion can result in the doctor back-tracking and slowing or adjusting the pace of the communication.

Remote interpreters may also interrupt to signal the need to end the consultation, usually because they have another booking or the consultation has extended significantly beyond the original booking time. This sometimes results in a side-negotiation between doctor and interpreter in which the interpreter 'grants' some extra time, or the doctor restructures part of the consultation:

Interpreter: Excuse me, I'm sorry, I will need to finish in ten minutes. I've got another booking.

Doctor: We should be finishing soon. Can you give me about fifteen minutes so that I can finish the examination and discuss treatment?

Interpreter: OK, we'll go as long as we can. I'll tell you when I have to hang up.

Through these communication acts, the telephone interpreter, speaking the language of the refugee patient, is able to demonstrate that they can exert authority in an arena where refugees frequently view themselves as without authority.

On occasion, this can work the other way around, with the patient exerting authority over the interpreter, who in the following account may have functioned as a proxy for the health system.

$\mathrm{Mr} \mathrm{X}$, an asylum seeker, came to the clinic after an emergency operation conducted in a hospital. He did not know why he had the operation, and 


\section{Christine Phillips}

had not had the consent form interpreted before he signed it. During the consultation, he became increasingly irritable, shaking his head at some of the word choices made by the interpreter (confusion of 'left' and 'right') making eye contact with the doctor as he did so. Fifteen minutes into the consultation, he made a hang up sign to the doctor, shaking his head. Mr X then commented on the minor mistakes made by the interpreter in broken English, and said that he was pleased that his wish to let the interpreter go had been met. The interpreter was fully competent and had previously interpreted consultations in the same language without issue.

In this case, $\mathrm{Mr} \mathrm{X}$, who was living in penury while he awaited the processing of his claim, and had just had a frightening experience when he felt his concerns were not recognized by the hospital, was able to exert some authority over the consultation by removing the interpreter. By contrast, in over 10 years of the author's practice, no refugee has ever requested that an on-site interpreter be removed in the middle of the consultation, though occasionally they have subsequently confided a wish not to have that interpreter again. This small act of 'speaking back to power' was made possible by the remoteness and anonymity of the interpreter.

The meta-communication about productive resettlement is established explicitly when the interpreter swaps information about their background with the patient, and implicitly through the background noises of the interpreter's life. In 19 per cent of the interpreted consultations audited, the consultation began with the interpreter, at the request of the patient, providing some details about where he or she had originally come from (I am unable to comment on the number of times a remote interpreter declined this request from a patient, though I am aware that they did do so on occasion). Neither the interpreter nor the patient swapped personal identifying details, but many noted that they came from the same town, or had spent time in the same refugee camp. These conversations tended to have a settling effect on the refugee, enabling them to enter a communication with someone who was located within a cultural frame of reference. This swapping of introductory details also happens with on-site interpreters while they wait with patients in the waiting room, but very rarely continues into the consultation.

On 10 occasions during the last five years, patients declined to have the interpreter after these introductory discussions, citing concerns about confidentiality or lack of trust of the interpreter because of his/her background. These instances of rejecting a remote interpreter are very small compared with the number who have requested one in preference to an on-site interpreter for the same reasons.

In the 265 consultations, there were 19 in which the interpreter made a comment directed to the patient designed to put them at ease, subsequently explained by either the patient or the interpreter.

A Persian language interpreter had trouble identifying a word she wanted to use. This led to her explaining to the patient that she was flipping through her 
dictionary trying to identify the English word (which was 'pause'). The interpreter then briefly discussed how learning English had been hard for her when she arrived, but she found it much easier after attending the governmentprovided English classes that the patient was also attending.

At interview, this was also commented on:

When I first came to [health service] English was too hard, because Australians speak very fast. The interpreters on the phone could talk English back to the doctor, even without seeing her. That interpreter told me that she learned it here and I would too [female, from Afghanistan].

Remote interpreters in Australia rarely do this work full-time. Most build interpreting into their lives, and it is the incursions of the soundscapes of these lives into the consultation that can convey the most powerful messages about the establishment of life in resettlement countries. Table 1 presents a summary of irruptions of background noise into the medical consultation captured in 85 out of 265 telephone consultations. Interpreters generally work from home, and the noises that emerge are the noises of home life: babies crying, children talking in the background, a doorbell ringing, a bird singing in the garden. Sometimes the interpreter is engaged elsewhere - a student in a lecture, a worker in a meeting, in transit between work and home. A consultation may begin with the interpreter telling the patient and doctor that they need to find a private space outside the lecture theatre, pull off the highway, or close the door of their office. If an interpreter was interrupted by an event in their own life (a child calling in the background, or a train passing the window), they briefly noted this in the consultation.

\section{Table 1}

Background Noise in Remote Interpreted Consultations, February-November 2011 $(\mathbf{n}=\mathbf{2 6 5})^{*}$

\begin{tabular}{lcl}
\hline $\begin{array}{l}\text { Type of } \\
\text { background noise }\end{array}$ & Number & Example \\
\hline $\begin{array}{l}\text { None } \\
\text { Ambient domestic } \\
\text { noise }\end{array}$ & 180 & $\begin{array}{l}\text { Clattering of crockery, doorbell ringing, other } \\
\text { phone ringing, making a cup of tea, birds } \\
\text { singing in cage/garden } \\
\text { Traffic noise }\end{array}$ \\
$\begin{array}{l}\text { Children } \\
\text { Bain going through tunnel, road traffic } \\
\text { Adults }\end{array}$ & 30 & $\begin{array}{c}\text { talking to each other } \\
\text { Requests to be left alone while interpreting (4); } \\
\text { Dispute with another adult (1) }\end{array}$ \\
Workplace & 11 & Walking down corridors, closing doors of offices \\
\hline
\end{tabular}

*More than one type of background noise could be heard in some consultations 


\section{Christine Phillips}

Noises like the interpreter's footsteps echoing in a corridor tended to have no impact on the consultation. Hearing children in the background tended to result in the patient and doctor sharing a smile, while those with babies crying or gurgling resulted in female patients initiating a side conversation with the interpreter about the age of the baby and its behaviour. On four occasions in this audit the background noise of traffic was so distracting the consultation was stopped. The only other occasion when the consultation was stopped because of background noise was the only actively negative incursion into a consultation. The consultation was with an unmarried woman who had arrived in Australia two months earlier. Over the telephone, an adult man was heard shouting angrily in the background at the interpreter, in a language that the patient understood, but the doctor did not. The interpreted consultation was stopped, another interpreter was contacted, and the doctor and patient then discussed verbal and physical violence within relationships, and the patient's view of norms within her culture and legal protections against violence. The intrusion of the angry adult via RTI derailed the consultation, which had been intended to focus on a general health assessment. It did, however, result in a conversation about women's rights and expectations, and led to the patient discussing her own expectations of marital partnerships after resettlement.

The meta-communication between refugee and interpreter addresses social identity and authority. The interpreter speaks the same language as the patient, and frequently they are able to establish other points of common experience (familiarity with the same camp, or home city, struggles to acquire English). The interpreter can thus be located within an imagined world which overlaps with the world as the refugee experiences it. The interpreter has an established life, demonstrated through the subtle soundscapes of domestic and working life, and can adopt an authoritative communicative stance in the consultation. They represent the establishment of selfhood and authority after resettlement. The fact that the interpreter is anonymous and disembodied again reinforces this meta-communication. They are the imagined other, rather than a specific person with a known domestic life, and their metacommunication signals to a time when the newly arrived refugee will also be working, enjoying small children, or listening to birds in a garden.

\section{New Interpreting Technologies and their Potential Impacts}

The futurist Raymond Kurtzweil proposed in 1990 that by 2010 telephone interpreting systems would be available to enable people who spoke different languages to speak to one another (Kurtzweil 1990). While this prediction has not been fulfilled, there is a great deal of interest in new software that aims to make the human interpreter redundant.

Computerized translation systems have existed since the 1950s (Hutchins 1986), though they have only recently become more user-friendly (Sproat 2010). Machine-based translation systems are used in online settings like 
chatrooms, and could be used in medical consultations where the doctor and patient were not in the same room. The online consultation departs from the current ideal model of doctor-patient communication (and emphasizes information exchange over examination), and few doctors have received formal training in effective communication for this type of consultation. Communication using translation software could make the human interpreter redundant; though other models could evolve in which the human interpreter participates in the consultation as a quality assurance agent, adjusting the results of the machine translation where necessary. For refugee patients who are literate in their spoken language, have access to the technology and a receptive health system, translation software may act to reinforce agency.

Speech-to-speech translating (SST) systems - the conversion of a speech signal in a source language into another speech signal in a target language-are one of the growth areas in interpreting systems (Anastasiou 2011). Most systems have been developed for small hand-held devices, and currently available prototypes include SST systems set up for a number of world languages paired with English.

One consideration for refugees is that these systems are only useful if they include their own language and recognize regional accents. Current SST systems are not sufficiently developed for speakers of minority languages or major languages with significant regional variations. However, in future SST systems are likely to be of significant value for resettlement countries which do not have established communities to act as interpreters. When SST systems become widely available, there is likely to be a defunding and winding down of the telephone interpreting industry. The SST communication environment, while accessible and useful, will not enable the subtle modelling of survival through resettlement which emerges through the meta-communication between patient and interpreter in RTI. The winding down of telephone interpreting infrastructure may mean that in those circumstances where SST systems are insufficient-and this is most likely to occur with minority languages of newly arrived refugees - telephone interpreting may be less accessible and/or more expensive.

Businesses providing remote interpreting are also exploring video interpreting using freeware such as Skype or ooVoo. This could harness some of the flexibility of telephone interpreting, allowing the interpreter to operate from home or any video console, while adding in the capacity for the interpreter to pick up visual information. The model of communication and metacommunication described in this article would suggest that video conferencing may have several limitations. The video interpreter is no longer anonymized. A person is introduced into the consultation, changing the dynamic between doctor and patient. Background noises are likely to be limited, as the interpreter will be working in a more contained space, and the interpreter may need to tread a line between the recessive presence of the on-site interpreter and the assertive verbal style of the telephone interpreter. The 
meta-communication between refugee and interpreter about selfhood and survival is likely to be watered down.

\section{Conclusion}

For refugees, encounters with doctors in settlement countries are encounters with power. The consultation provides an entrée into the health system's network of services and therapies, and to non-medical resources such as housing and income support. In Australia, most refugees begin their contact with the health services with the assistance of remote telephone interpreters.

Despite the widespread view held by doctors that on-site interpreters are always preferable to remote interpreters, refugees may be better served by telephone interpreters through their resettlement. Remote interpreting services have a larger pool of interpreters with more availability, and they offer extended hours. An additional benefit of the telephone interpreter is their meta-communicative function. I have argued in this article that consultations with refugees using remote telephone interpreters are framed by two metacommunications: recognition of their individual needs by the polity, and the safe negotiation of identity through resettlement. Some of this metacommunication relies on the interpreter being geographically distant and anonymized, and would be altered if on-site interpreters were used.

Language support services using telephone interpreters are experiencing rapid growth. At the same time, computerized systems in development offer the possibility of communication without interpreters, particularly through speech-to-speech translation systems. Beguiling as these may be, it is possible that speakers of minority languages, such as refugees, may not be catered for by this technological development. The widespread uptake of SST systems is likely to lead to a decline in investment in RTI infrastructure and workforce. The result may be a diminution in language support for refugees, and a thinning of the rich meta-communication about welcome and social identity that has accompanied the widespread use of consultations using remote telephone interpreting.

\section{Acknowledgements}

I am grateful to my colleagues Katrina Anderson, Joo-Inn Chew, Emily Lambert and James Eldridge for feedback on the ideas in this article.

AGER, A. and STRANG, A. (2008) 'Understanding Integration: A Conceptual Framework'. Journal of Refugee Studies 21(2): 166-191.

ALDOUS, J., BARDSLEY, M., DANIELL, R., GAIR, R., JACOBSON, B., LOWDELL, C., MORGAN, D., STORKEY, M. and TAYLOR, G. (1999) Refugee Health in London: Key Issues for Public Health. London: Health of Londoners Project.

ANASTASIOU, D. (2011) 'Survey on Speech, Machine Translation and Gesture in Ambient Assisted Living'. Presentation at: 'Métiers et technologies de la traduction: quelles 
convergences pour l'avenir?' Paris, March 2011. http://lodel.irevues.inist.fr/tralogy/index. php?id=125. Accessed 4 January 2013.

ANDRES, D. and FALK, S. (2009) 'Remote and Telephone Interpreting'. In Andres, D. and Pöllabauer, S. (eds) Spürst Du wie der Bauch rauf runter?/Is everything all topsy turvy in your tummy? Fachdolmetschen im Gesundheitsbereich/Health Care Interpreting. München: Martin Meidenbauer, pp. 9-27.

BATESON, G. (1951) 'Information and Codification: A Philosophical Approach'. In Ruesch, J. and Bateson, G. (eds) Communication: The Social Matrix of Psychiatry. New York: WW Norton \& Co, pp. 168-211.

BAUMAN, R. (1975) 'Verbal Art as Performance'. American Anthropologist 77(2): 290-311.

BIRD, S. (2008) 'Lost Without Translation'. Australian Family Physician 37: 1023-1024.

BURBANO O'LEARY, S. C., FREDERICO, S. and HAMPERS, L. C. (2003) 'The Truth about Language Barriers: One Residency Programme's Experience'. Pediatrics 111(5 Pt1): e569-573.

COLIC-PEISKER, V. and TILBURY, F. (2003) " "Active" and "Passive" Resettlement: The Influence of Support Services and Refugees' Own Resources on Resettlement Style'. International Migration 41(5): 61-91.

CORREA-VELEZ, I., SUNDARARAJAN, V., BROWN, K. and GIFFORD, S. M. (2007) 'Hospital Utilisation Among People Born in Refugee-source Countries: An Analysis of Hospital Admissions 1998-2004'. Medical Journal of Australia 186: 577-580.

DAVIDSON, B. (2000) 'The Interpreter as Institutional Gatekeeper: The Socio-linguistic Role of Interpreters in Spanish-English Medical Discourse'. Journal of Socio-Linguistics 4(3): 375-405.

DAVIDSON, B. (2001) 'Questions in Cross-linguistic Medical Encounters: The Role of the Hospital Interpreter'. Anthropological Quarterly 74(4): 170-178.

DEPARTMENT OF IMMIGRATION AND CITIZENSHIP (2011) Annual Report 2010-2011. Canberra: Government of Australia http://www.immi.gov.au/about/reports/annual/2010-11/ html/. Accessed 6 January 2013.

DEPARTMENT OF IMMIGRATION AND CITIZENSHIP (2012) Annual Report 2011-2012. Canberra: Government of Australia http://www.immi.gov.au/about/reports/annual/2011-12/ $\mathrm{html} /$. Accessed 6 January 2013.

FASSIN, D. and RECHTMANN, R. (2009) The Empire of Trauma: An Inquiry into the Nature of Victimhood. (trans. Gomme, R.) New Jersey: Princeton University Press.

GREENHALGH, T., ROBB, N. and SCAMBLER, G. (2006) 'Communicative and Strategic Functions in Interpreted Consultations in Primary Health Care: A Habermasian Perspective'. Social Science and Medicine 63(5): 1170-1187.

HORNBERGER, J., ITAKURA, H. and WILSON, S. R. (1997) 'Bridging Language and Cultural Barriers Between Physicians and Patients'. Public Health Reports 112(5): 410-417.

HORNBERGER, J. C., GIBSON, C. D. Jr, WOOD, W., DEQUELDRE, C., CORSO, I., PALLA, B. and BLOCH, D. A. (1996) 'Eliminating Language Barriers for Non-English Speaking Patients'. Medical Care 34: 845-856.

HSIEH, E. (2006) 'Understanding Medical Interpreters: Reconceptualising Bilingual Health Communication'. Health Communication 20: 177-186.

HSIEH, E. and HONG, S. J. (2010) 'Not All Are Desired: Providers' Views of Interpreters' Emotional Support for Patients'. Patient Education and Counselling 81: 192-197.

HUANG, Y. T. and PHILLIPS, C. (2009) 'Telephone Interpreters in General Practice: Bridging the Barriers to Their Use'. Australian Family Physician 38(6): 443-446.

HUTCHINS, J. (1986) Machine Translation: Past, Present, Future. Chichester: Ellis Horwood.

INVIVO (2008) 'Interpreters in Medical Practice'. http://invivo.com.au/newsletter1707_2.html Accessed 4 January 2013.

JONES, D. and GILL, P. (1998) 'Breaking Down Language Barriers'. British Medical Journal 316: 1476.

KELLY, N. (2008) Telephone Interpreting: A Comprehensive Guide to the Profession. Bloomington, Indiana: Trafford Publishing. 
KELLY, N. and DE PALMA, D. A. (2012) 'The Top 100 Language Service Providers'. Common Sense Advisory 31 May 2012. http://www.commonsenseadvisory.com/Portals/0/downloads/ 120531_QT_Top_100_LSPs.pdf Accessed 4 January 2013.

KELly, N., PALMER, D. A. and STEWART, R. G. (2012) The Languages Services Market: 2012. Lowell, MA: Common Sense Advisory, Inc.

KHAWAJA, N. G., WHITE, K. M., SCHWEITZER, R. and GREENSLADE, J. (2008) 'Difficulties and Coping Strategies of Sudanese Refugees: A Qualitative Approach'. Transcultural Psychiatry 45(3): 489-512.

KO, L. (2006) 'The Need for Long-Term Empirical Studies in Remote Interpreting Research. A Case Study of Telephone Interpreting'. Linguistica Antverpiensia: New Series 5: 325-338.

KUO, D. and FAGAN, M. J. (1999) 'Satisfaction with Methods of Spanish Interpretation in an Ambulatory Care Clinic'. Journal of General Internal Medicine 14(9): 547-550.

KURTZWEIL, R. (1990) The Age of Intelligent Machines. Cambridge, MA: MIT Press.

LANGUAGE LINE (2010) 'Top 20 US Cities in Volume of Language Line Services Telephone Interpreter Requests 2009 vs 2008'. February 23. http://healthcare.languageline.com/top20 Accessed 4 January 2013.

LEANZA, Y., BOIVIN, I. and ROSENBERG, E. (2010) 'Interruptions and Resistance: A Comparison of Medical Interpretations with Family and Trained Interpreters'. Social Science and Medicine 70(12): 1888-1895.

LEE, L. J., BATAL, H. A., MASELLI, J. H. and KUTNER, J. S. (2002) 'Effect of Spanish Interpretation Method on Patient Satisfaction in an Urban Walk-in Clinic'. Journal of General Internal Medicine 17: 641-646.

LOCATIS, C., WILLIAMSON, D., GOULD-KABLER, C., ZONE-SMITH, L., DETZLER, I., ROBERSON, J., MAISIAK, R. and ACKERMAN, M. (2010) 'Comparing In-person, Video and Telephonic Medical Interpreting'. Journal of General Internal Medicine 25: 345-350.

MARLOWE, J. M. (2010) 'Beyond the Discourse of Trauma: Shifting the Focus of Sudanese Refugees'. Journal of Refugee Studies 23(2): 183-198.

MCKEARY, M. and NEWBOLD, B. (2010) 'Barriers to Care: the Challenges for Canadian Refugees and Their Health Care Providers'. Journal of Refugee Studies 23(4): 523-554.

MEDICAL BOARD OF AUSTRALIA (2010) Good Medical Practice: A Code of Conduct for Doctors in Australia. http://www.medicalboard.gov.au/Codes-Guidelines-Policies.aspx Accessed 4 January 2013.

NATIONAL ACCREDITATION AUTHORITY FOR TRANSLATORS AND INTERPRETERS (2010) 'New Interpreters Project: Information Booklet and Application Form'. Canberra: NAATI. http://www.naati.com.au/PDF/Booklets/BOOKLET_N.pdf Accessed 4 January 2013.

O'HAGAN, M. and ASHWORTH, D. (2002) Translation-Mediated Communication in a Digital World: Facing the Challenges of Globalisation and Localisation. Clevedon, UK: Multilingual Matters Ltd.

PENDleTON, D., SCHOFIELD, T., TATE, P. and HAVELOCK, P. (2003) The New Consultation: Developing Doctor-Patient Communication. Oxford: Oxford University Press.

PETERSON, P., SACKEY, D., CORREA-VELEZ, I. and KAY, M. (2010) Building Trust: Delivering Health Care to Newly Arrived Refugees. Brisbane: Mater UQ Service for Primary Health Integration $\quad \mathrm{http} / / /$ materonline.org.au/services/refugee/clinical-resources-and-publications Accessed 4 January 2013.

PHILLIPS, C. (2010) 'Working with Interpreters: A Guide for GPs'. Australian Family Physician 39(4): 188-195.

PHILliPS, C. B. and TRAVAGLiA, J. (2011) 'Low Levels of Uptake of Free Interpreters by Australian Doctors in Private Practice: Secondary Analysis of National Data'. Australian Health Review 35(4): 475-479.

ROSENBERG, B. A. (2007) 'A Data Driven Analysis of Telephone Interpreting'. In Wadensjö, C., Englund, D. B. and Nilsson, A.-L. (eds) The Critical Link 4. Professionalisation of Interpreting in the Community. Amsterdam: John Benjamins, pp. 65-78. 
ROYAL AUSTRALIAN COLLEGE OF GENERAL PRACTICE (2010) Standards for General Practice, $4^{\text {th }}$ edition. http://www.racgp.org.au/standards/123 Accessed 4 January 2013.

SPROAT, R. W. (2010) Language, Technology and Society. Oxford: Oxford University Press.

TRANSLATING AND INTERPRETING SERVICE (2010) 'Doctors Priority Line: A Growing Service'. Talking TIS August 2010, 3. http://www.immi.gov.au/living-in-australia/help-withenglish/help_with_translating/_pdf/talking-tis-autumn-10.pdf. Accessed 4 January 2013.

WADENSJÖ, C. (1999) 'Telephone Interpreting and the Synchronization of Talk in Social Interaction'. Translator: Studies in Intercultural Communication 5: 247-264.

WILMOT, W. W. (1980) 'Meta-communication: A Re-examination and an Extension'. In Nimmo, D. (ed.) Communication Yearbook 4. New Brunswick, NJ: Transaction Books, pp. $61-70$.

YAWMAN, D., Mcintosh, S., FernandeZ, D., AUlinger, P., Allan, M. and WEITZMAN, M. (2006) 'The Use of Spanish by Medical Students and Residents at One University Hospital'. Academic Medicine 81(5): 468-473. 